\title{
Viscoelastic and Dynamic Characteristics of Wood- melamine-urea-formaldehyde Composites Prepared by In Situ Polymerization
}

Qian Lang,* Chao Zhang, Chuanhao Liu, Huimin Zhang, Shengming Zhang, Longhai Li, and Haitao Chen

The viscoelastic behavior and the dynamic mechanical properties were studied for wood-melamine-urea-formaldehyde composites prepared from fast-growing poplars using in situ polymerization. The changes in stress relaxation $(\mathrm{SR})$, storage modulus $\left(E^{\prime}\right)$, and damping parameter (tan $\delta$ ) were considered. The relationship between the dynamic mechanical properties and the modifier concentration was also studied. The SR value decreased as the modifier content increased in all the samples examined. The urea content had a greater impact than the melamine-ureaformaldehyde mixture content on the SR value of the wood samples. A similar trend was observed for $E$. The modified wood samples exhibited a higher $\tan \delta$. The results confirmed that a better interfacial interaction between melamine-urea-formaldehyde and wood fiber contributed to the improvement of mechanical properties in the fast-growing poplar wood.

DOI: 10.15376/biores.17.1.1015-1030

Keywords: Viscoelastic properties; Copolymerization; Fibers; Mechanical properties

Contact information: Faculty of Engineering, Northeast Agricultural University, Changjiang Road 600, Xiangfang 150030, Haerbin, China; *Corresponding author: langqian4521@ 126.com

\section{INTRODUCTION}

Over the past several decades, wood materials have received remarkable attention in the marketplace because of their advantages over established materials. Wood possesses higher specific strength and has a higher modulus of elasticity compared to other materials (Zhu et al. 2017; Düzkale Sözbir et al. 2021). However, natural wood has poor compatibility, a tendency to form aggregates during processing, and a low resistance to moisture, which reduces its use as an elastic material.

Chemical modification of wood is a common method used to reduce or eliminate its undesirable properties. Chemical treatments could permanently alter the nature of the fiber cell walls by grafting polymers onto the fiber surface, or by bulking or cross-linking within the fiber cell walls. Movement of chemicals in and out of the cell walls has important implications in wood treatments and their performances. Chemical modification could make the fiber cell walls more dimensionally stable, reduce water sorption, and increase resistance against fungal decay (Kumar 1994; Kaymakci and Bayram 2021). The chemicals used must impregnate into the cell lumen, cell wall, or the combination of both so that they can react with the available hydroxyl groups in the wood cell wall (Hon and Qu 1989). The polymer type used in wood modification is typically a thermosetting resin, such as phenol formaldehyde $(\mathrm{PF})$, urea formaldehyde $(\mathrm{UF})$, melamine formaldehyde $(\mathrm{MF})$, or epoxy resins. Following the wood modification, the properties of wood, such as dimensional 
stability, durability, mechanical properties, and hardness, are improved to meet specific end-use requirements (Tanimoto and Nakano 2012; Liu et al. 2014).

Polymeric materials are commonly classified as a viscoelastic materials, meaning they exhibit time-dependent stress-relaxation properties under various strain loadings. An excessive relaxation of the stress in a polymer-based structural component could render its performance non-functional (Tanimoto and Nakano 2012). Wood is a unique composite that consists of three structural polymers, cellulose, hemicelluloses, and lignin (Kelley et al. 1987). At the macromolecular level, wood is described as a two-phase composite of elastic fibers, consisting of cellulose and hemicellulose, and a viscoelastic matrix substance comprised of lignin and hemicelluloses (Obataya et al. 1998).

Dynamic mechanical analysis (DMA) has become a widely used technique for determining the interfacial characteristics of these heterogeneous polymeric systems (George et al. 1996). The DMA is defined as a technique where the storage modulus $E^{\prime}$ (elastic response) and the loss modulus $E^{\prime \prime}$ (viscous response) of the sample under an oscillating load are monitored against time, temperature, or frequency of oscillation (Shinoj et al. 2011). The DMA measurements can be conducted over a wide range of temperature, helping to study the viscoelastic behavior of the polymer systems, in particular the glass transition region in the fiber-reinforced composites. Materials respond to the applied force by exhibiting either elastic behavior, viscous behavior, or a combination of both, called viscoelastic behavior. Viscoelastic behavior of wood is typically determined by the DMA and is important because it reveals the proper temperature setting that wood tolerates during specific processing operations. Several studies have focused on the DMA properties of wood after modification. Fabiyi et al. (2011) conducted a study on the viscoelastic properties of ethylene glycol plasticized Nigerian plantation grown teak (Tectona grandis) wood. Kuo et al. (2009) investigated the effects that material compositions have on the mechanical properties of wood-plastic composites (WPCs) manufactured via injection molding. The results showed that the mechanical properties and the $E^{\prime}$ values were the highest and the $\tan \delta$ values were the lowest when the SPF (spruce, pine, and fur) wood flour content was $47 \%$. This suggests that a wood flour content of less than $50 \%$ could be optimal for the manufacturing of WPCs.

The aim of this study was to investigate the changes that occur in the dynamic modulus and the viscoelastic properties of fast-growing wood-melamine-ureaformaldehyde composites, compared to untreated woods. The authors evaluated the dynamic mechanical properties of the fast-growing polar wood via various parameters. The change of stress-relaxation over various wood modifier contents were analyzed. The results showed that the plasticity of wood improved after chemical modification.

\section{EXPERIMENTAL}

\section{Materials}

Formaldehyde (mass fraction $37 \%$ to $40 \%$ ), melamine (99\% purity), and ammonia were obtained from Beijing Chemical Reagent Ltd, China.

Fresh-cut fast-growing poplars (Populus davidiana) were obtained from Hebei Province, China. The poplar samples used for the study were approximately 7 years old and $35 \mathrm{~cm}$ in diameter. The boles were relatively straight and practically free of decay. The initial moisture contents of the natural wood samples ranged from $70 \%$ to $80 \%$.

Lang et al. (2022). "Wood-MUF composite properties," BioResources 17(1), 1015-1030. 1016 


\section{Preparation of Chemical Wood Modifier}

The wood modifier was prepared as described by Lang et al. (2014). Urea (60\% $\mathrm{w} / \mathrm{w})$, formaldehyde $(25 \% \mathrm{w} / \mathrm{w})$, and ammonia $(15 \% \mathrm{w} / \mathrm{w})$ were mixed in a reactor using a mechanical agitator to form the urea-formaldehyde (UF) pre-polymer. An adequate amount of melamine was added to the melamine-urea-formaldehyde pre-polymer (MUF), and then the mixture was heated at 55 to $60^{\circ} \mathrm{C}$ for $2 \mathrm{~h}$ with stirring. The $\mathrm{pH}$ of this solution was adjusted to 7 to 8 by adding sodium hydroxide and hydrochloric acid solutions. The prepared pre-polymer had a density of $1.5 \mathrm{~g} / \mathrm{cm}^{3}, \mathrm{pH}$ of 9.0 , viscosity of $12 \mathrm{mPa} \cdot \mathrm{s}$, solid content of $57.84 \%$, and free formaldehyde content of $0.05 \mathrm{mg} / 100 \mathrm{~g}$. The chemical formulation for the wood impregnation is presented in Table 1 .

Table 1. Formulation for Wood Modification

\begin{tabular}{|c|c|c|c|}
\hline Sample Number & MUF (\%) & Urea (\%) & Catalyst (\%) \\
\hline Natural wood & 0 & 0 & 0 \\
\hline A & 15 & 15 & 5 \\
\hline B & 20 & 15 & 5 \\
\hline C & 25 & 15 & 5 \\
\hline D & 15 & 20 & 5 \\
\hline E & 20 & 20 & 5 \\
\hline F & 25 & 20 & 5 \\
\hline G & 15 & 25 & 5 \\
\hline H & 20 & 25 & 5 \\
\hline I & 25 & 25 & 5 \\
\hline
\end{tabular}

\section{Preparation of the Wood-melamine-urea-formaldehyde Composites}

The dimensions of wood samples used for impregnation were $15 \mathrm{~cm}$ in diameter and $60 \mathrm{~cm}$ in length. The fresh poplar wood was impregnated using a vacuum machine under $0.9 \mathrm{MPa}$ for $1.5 \mathrm{~h}$. The impregnated samples were cut into blocks of $5 \mathrm{~cm} \times 10 \mathrm{~cm}$ $\times 60 \mathrm{~cm}(\mathrm{~T} \times \mathrm{R} \times \mathrm{L})$ for the drying process.

\section{Stress Relaxation (SR) Analysis}

Specimens of dimensions $1 \mathrm{~cm} \times 1 \mathrm{~cm} \times 1 \mathrm{~cm}(\mathrm{~T} \times \mathrm{R} \times \mathrm{L})$ were scanned in a TAQ 800 (Mode of SR TTS; TA Instruments, New Castle, DE, USA) at $30^{\circ} \mathrm{C}$, with a relative humidity (RH) of 50\%. The compression rate of the wood samples was approximately $10 \%$. Five replicates were used for each treatment.

\section{Dynamic Mechanical Properties}

Rectangular natural and modified wood samples $(50 \mathrm{~mm} \times 10 \mathrm{~mm} \times 5 \mathrm{~mm})$ with a $10 \%$ compression ratio were examined on a DMA-242 analyzer (TA Instrument, New Castle, DE, USA) at ambient air atmosphere. The $E^{\prime}$ and $\tan \delta$ were measured with a threepoint flexure test at a heating rate of $2{ }^{\circ} \mathrm{C} /$ min with a temperature range between 30 and $180{ }^{\circ} \mathrm{C}$. The initial static force was $20 \mathrm{~N}$, and the dynamic force was $10 \mathrm{~N}$. Frequency sweeps were performed between 1 and $2 \mathrm{~Hz}$. A static stress of $0 \mathrm{~N}$, deformation amplitude of $50 \mu \mathrm{m}$, load of $4 \mathrm{~N}$, and a scale factor of 1.3 were used. Five replicates were tested for each treatment and the error was less than $1 \%$. 


\section{RESULTS AND DISCUSSION}

\section{SR Analysis}

The SR analysis is an effective means of characterizing the dynamics of polymer systems and assists in demonstrating the transient network behavior. Figure 1 shows the SR spectra with various modifier contents. The SR value of the modified wood was successively lower than the natural wood, where the SR value decreased as the amount of MUF content was increased. Figure 1(a) shows that the initial SR value was relaxed to $92 \%$ (Sample A), 91\% (Sample B), and 89\% (Sample C) when the MUF content ranged from $15 \%$ to $25 \%$. The SR value showed the same trend with an equal urea content. The value of SR decreased to 92\% (Sample A), 90\% (Sample D), and 87\% (Sample G) as the urea content was increased, as shown in Fig. 1(d). The amount of urea demonstrated a remarkable effect that was greater than the effect that the MUF content had on the SR value of the wood samples. Sample G showed that the SR value decreased to 87\%, while the SR value of sample I decreased to $75 \%$.

Wood is a polymeric material in which hydrogen bonds serve as the connection between the macromolecular chains of wood fibers (Sreekala et al. 2001). The urea and the MUF are polar molecules that penetrate the amorphous structure of cellulose and form hydrogen bonds. The penetration of the modifier destroyed the macromolecular chains in wood and regenerated the hydrogen bonds. The urea and the MUF contained a large number of $-\mathrm{NH}_{2}$ and $-\mathrm{OH}$ groups, which increased the combination between the intermolecular hydrogen bonds and the wood modifier. The increased cohesion between the wood fibers was attributed to the residual stress value of the wood. Following the modification, the decreased SR value of wood confirmed that the wood modifier penetrated the wood cell and a chemical reaction occurred between the $-\mathrm{NHCH}_{2} \mathrm{OH}$ functional groups from the MUF and the wood carboxyl $\mathrm{C}=\mathrm{O}$ group. The $-\mathrm{OH}$ groups and the $-\mathrm{NH}_{2}$ groups from the MUF were in situ polymerized with the hydroxyl groups (wood). The covalently cross-linked network had potential for improving the dimensional stability (Lang et al. 2013). The lower SR value of the material indicated that the material had an uneasilydeformed stability and superior mechanical properties.

\section{Storage Modulus ( $E)$ Analysis}

Dynamic mechanical analysis is a useful technique that provides information on the mechanical behavior, molecular relaxations, as well as interactions taking place in the materials formed as the temperature varies (Liu et al. 2008; Kiziltas et al. 2011). Figure 2 shows the changes in the $E^{\prime}$ of wood over various concentrations of MUF and urea. This decreasing trend of modulus is characteristic of the viscoelastic behavior of wood (Morlat et al. 1999; Pothan et al. 2003). As the content of wood modifier was increased, the $E^{\prime}$ in the samples decreased gradually between 50 and $120{ }^{\circ} \mathrm{C}$. Figure 2 (a) shows the $E^{\prime}$ value of wood with $15 \%, 20 \%$, and $25 \%$ MUF contents, which changed to 6700,7200 , and 7400 $\mathrm{MPa}$, respectively. The $E^{\prime}$ value of the modified wood samples was lower than the natural wood sample at $120^{\circ} \mathrm{C}$.

Figure 2 shows that the glass transition occurred around 50, 75, 120, 80, and $70{ }^{\circ} \mathrm{C}$ for samples A, B, E, F, and G, respectively. The modulus value remained unchanged afterwards. There was no noteworthy transition that occurred in the samples $\mathrm{C}, \mathrm{D}, \mathrm{H}$, and I. The decreasing rate of $E^{\prime}$ in samples $\mathrm{C}, \mathrm{D}, \mathrm{H}$, and I were lower than samples A, B, E, F, and $\mathrm{G}$, demonstrating that the transition temperature was related to the curing degree of wood modifier solution during the modification.

Lang et al. (2022). "Wood-MUF composite properties," BioResources 17(1), 1015-1030. 1018 


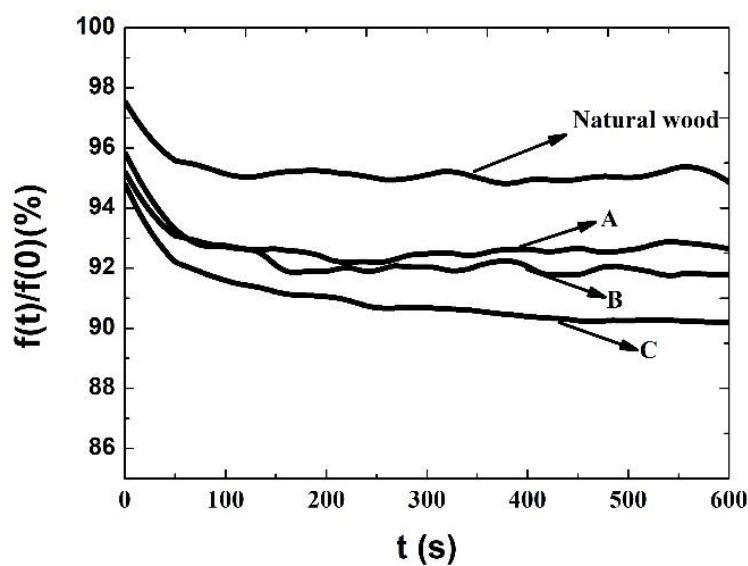

(a)

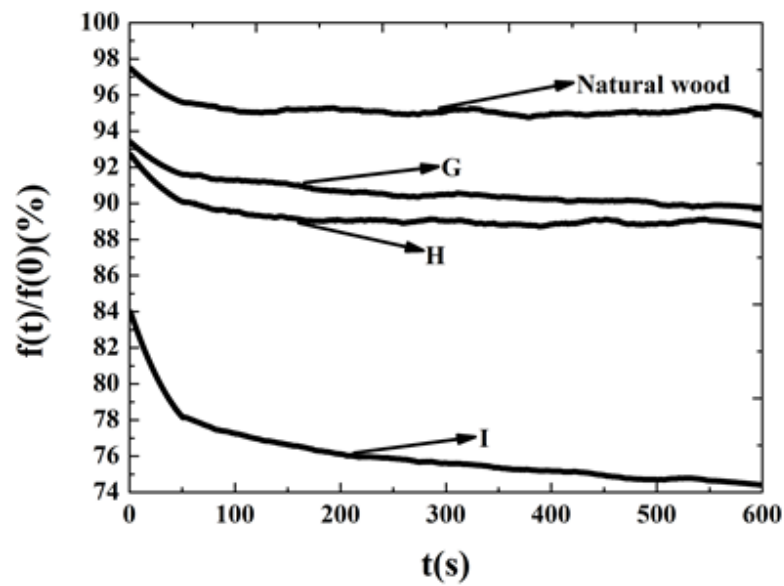

(c)

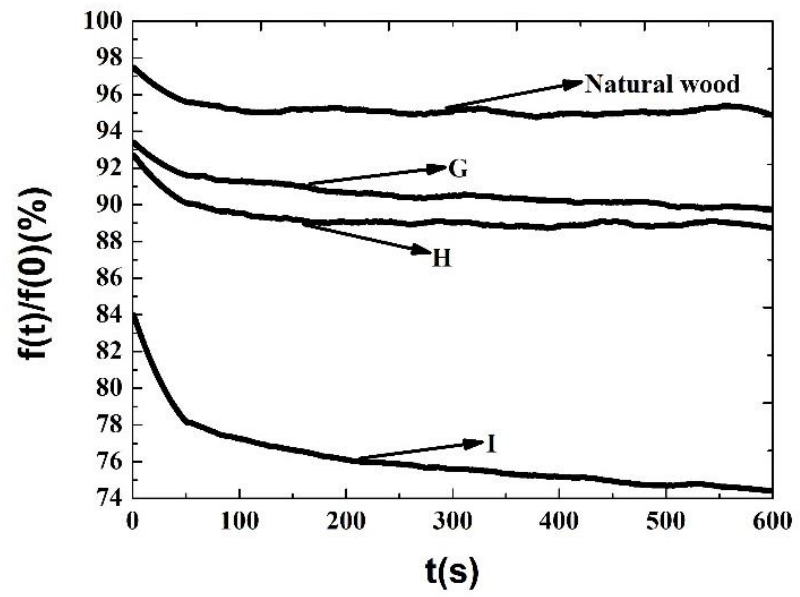

(e)

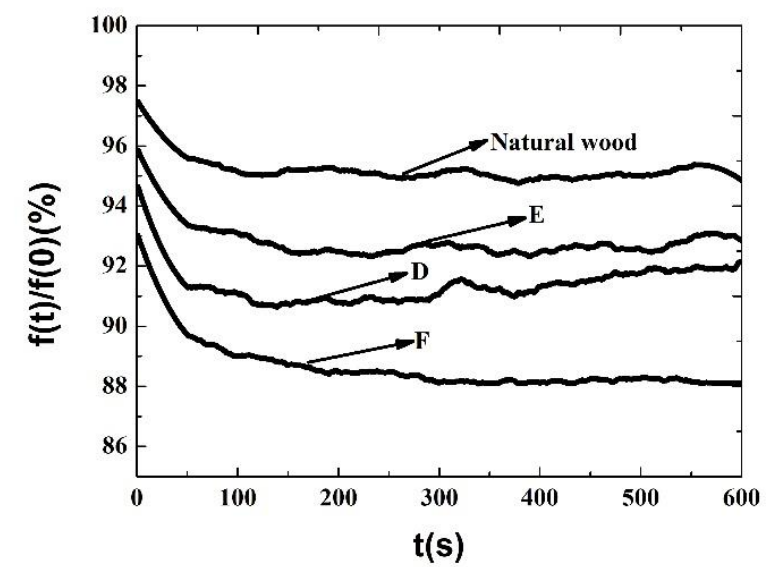

(b)

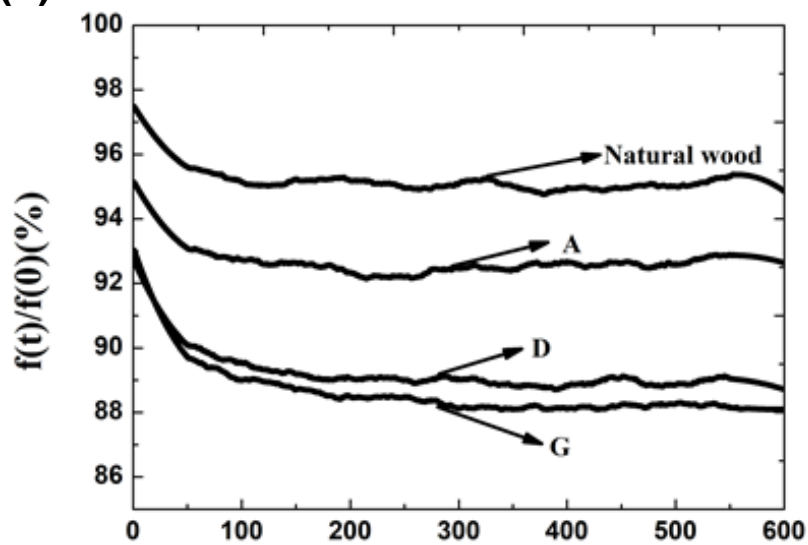

$t(s)$

(d)

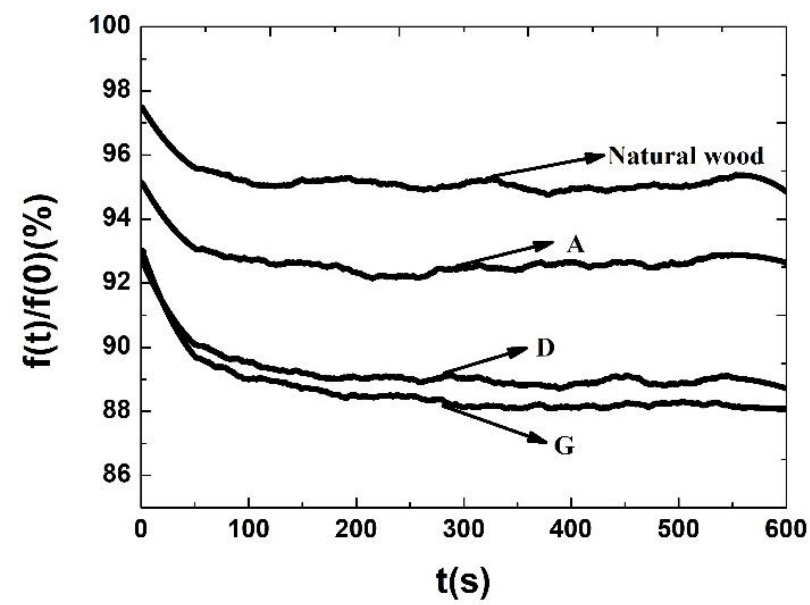

(f)

Fig. 1. Stress relaxation curves of natural and modified wood: (a) 15\% urea; (b) 20\% urea;

(c) $25 \%$ urea; (d) $15 \%$ MUF; (e) $20 \%$ MUF; and (f) $25 \%$ MUF contents 
The decreasing trend in $E^{\prime}$ resulted from the increased molecular mobility of the wood cell wall polymers at high temperatures (Ou et al. 2014). The increase in $E^{\prime}$ was observed for the modified wood. The modifier molecules cross-linked the growing linear chains during the curing process and thus tightened the structure of wood and added restrictions to the molecular motions in the wood. The $-\mathrm{OH}$ groups from the MUF molecules increased the hydrogen bond formations and restricted the molecular rotations at lower temperatures.
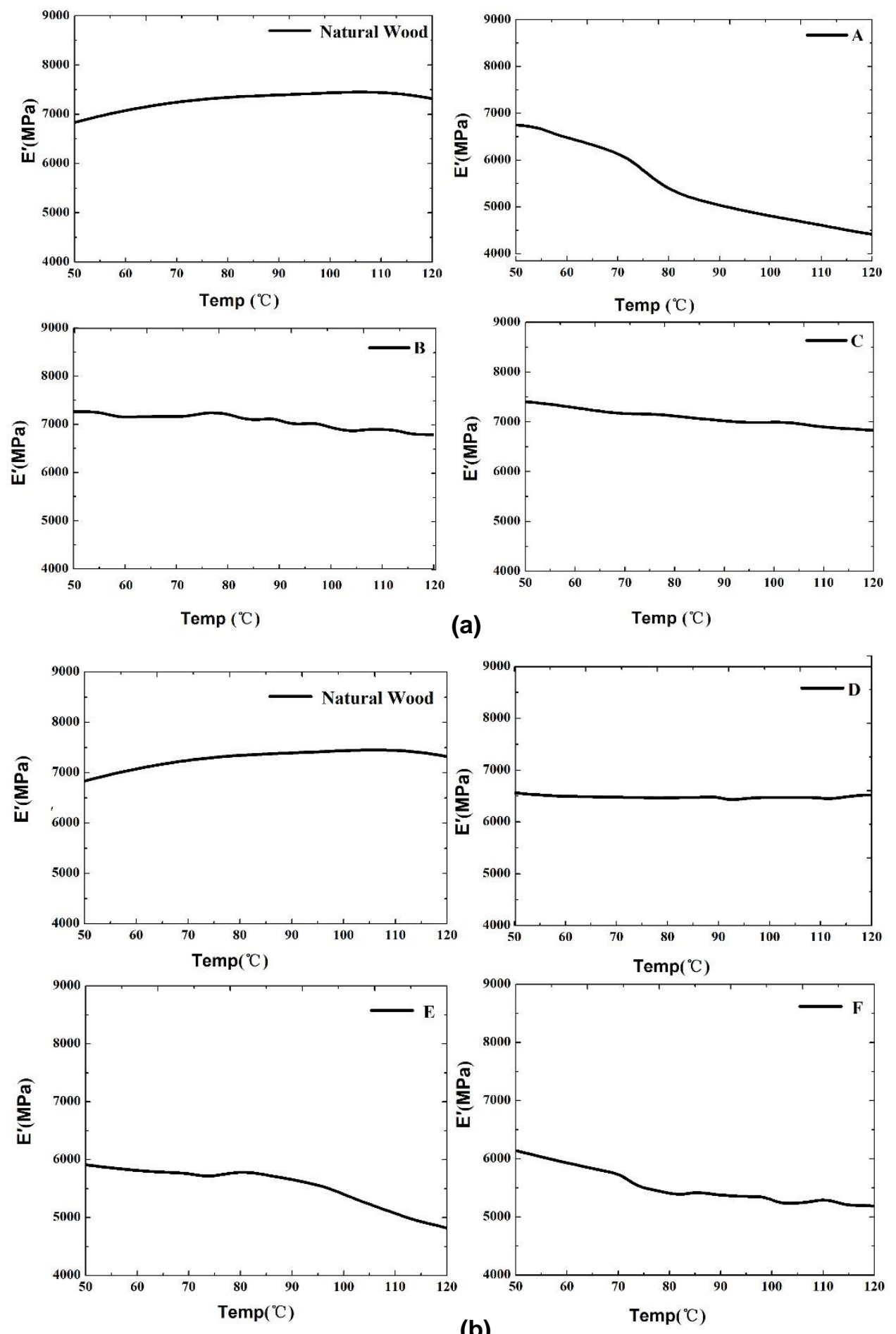

(b) 

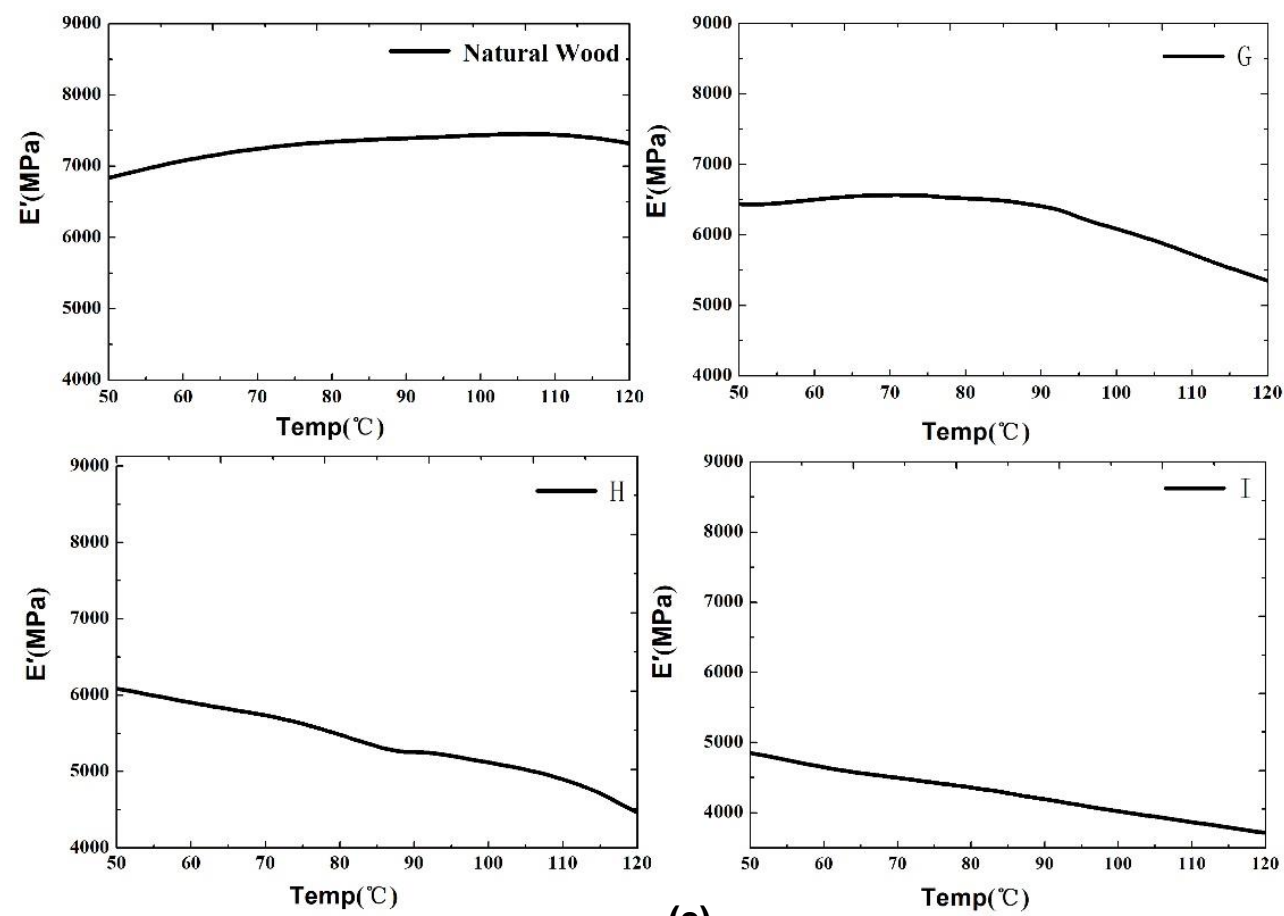

(c)
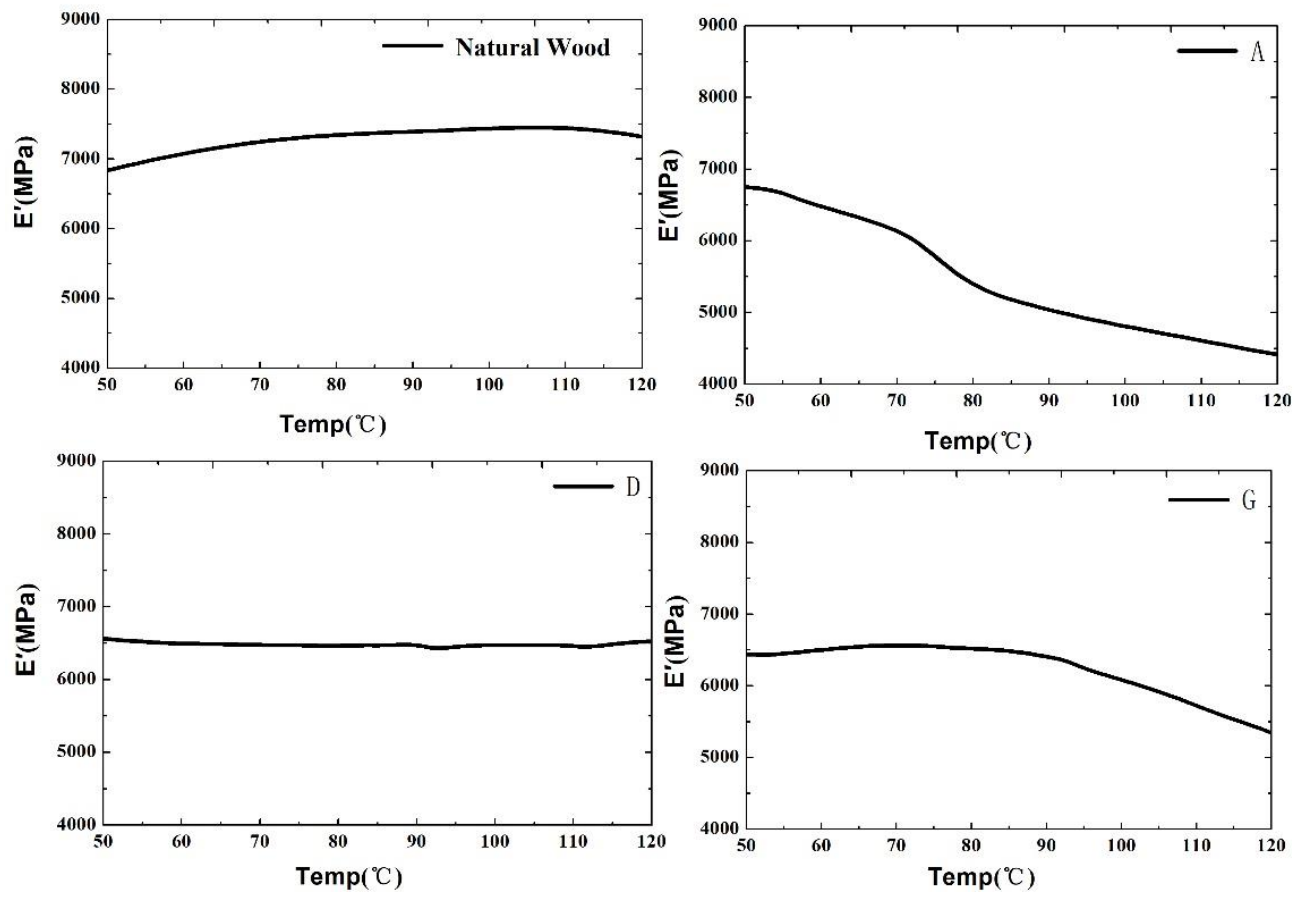

(d) 

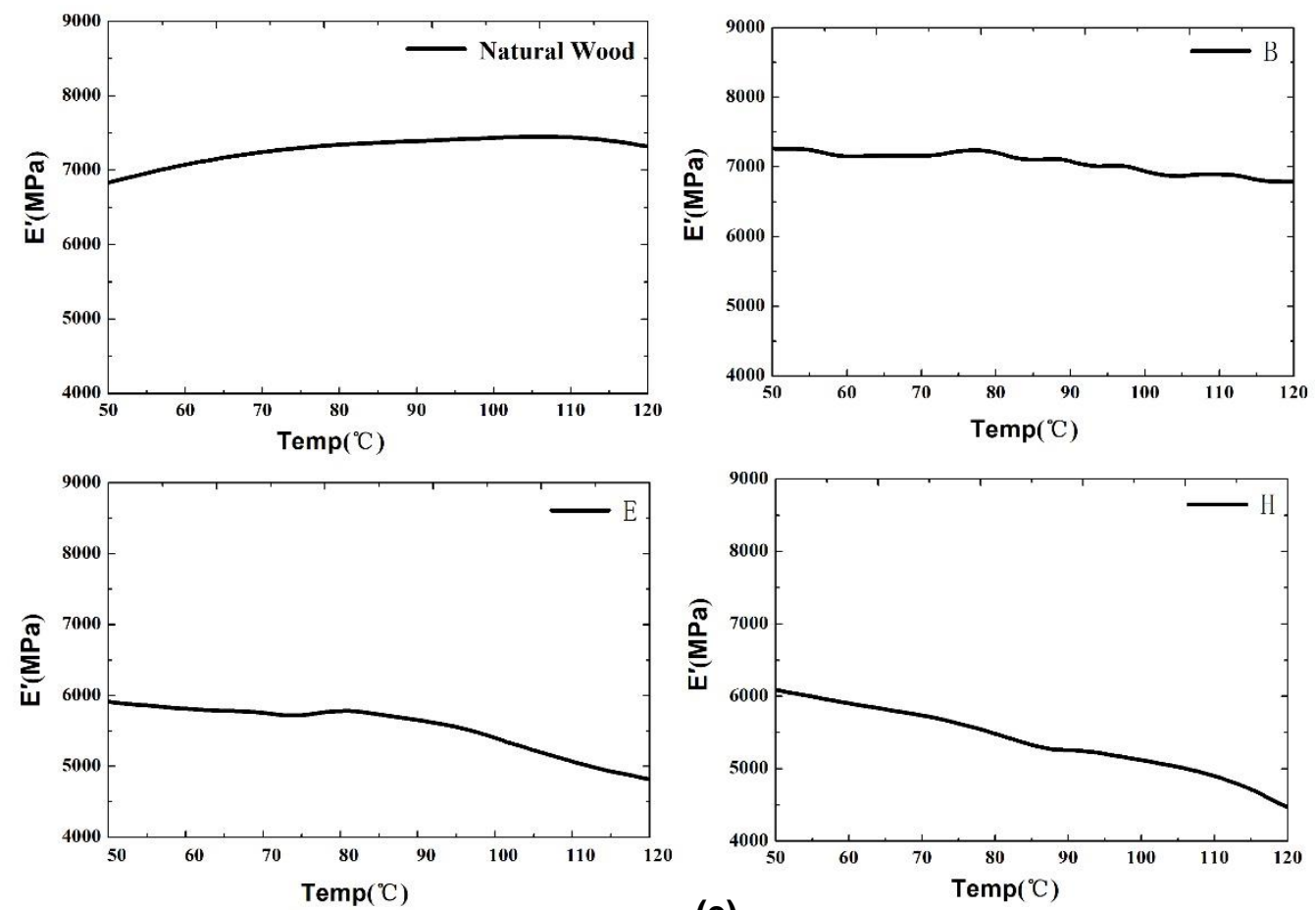

(e)
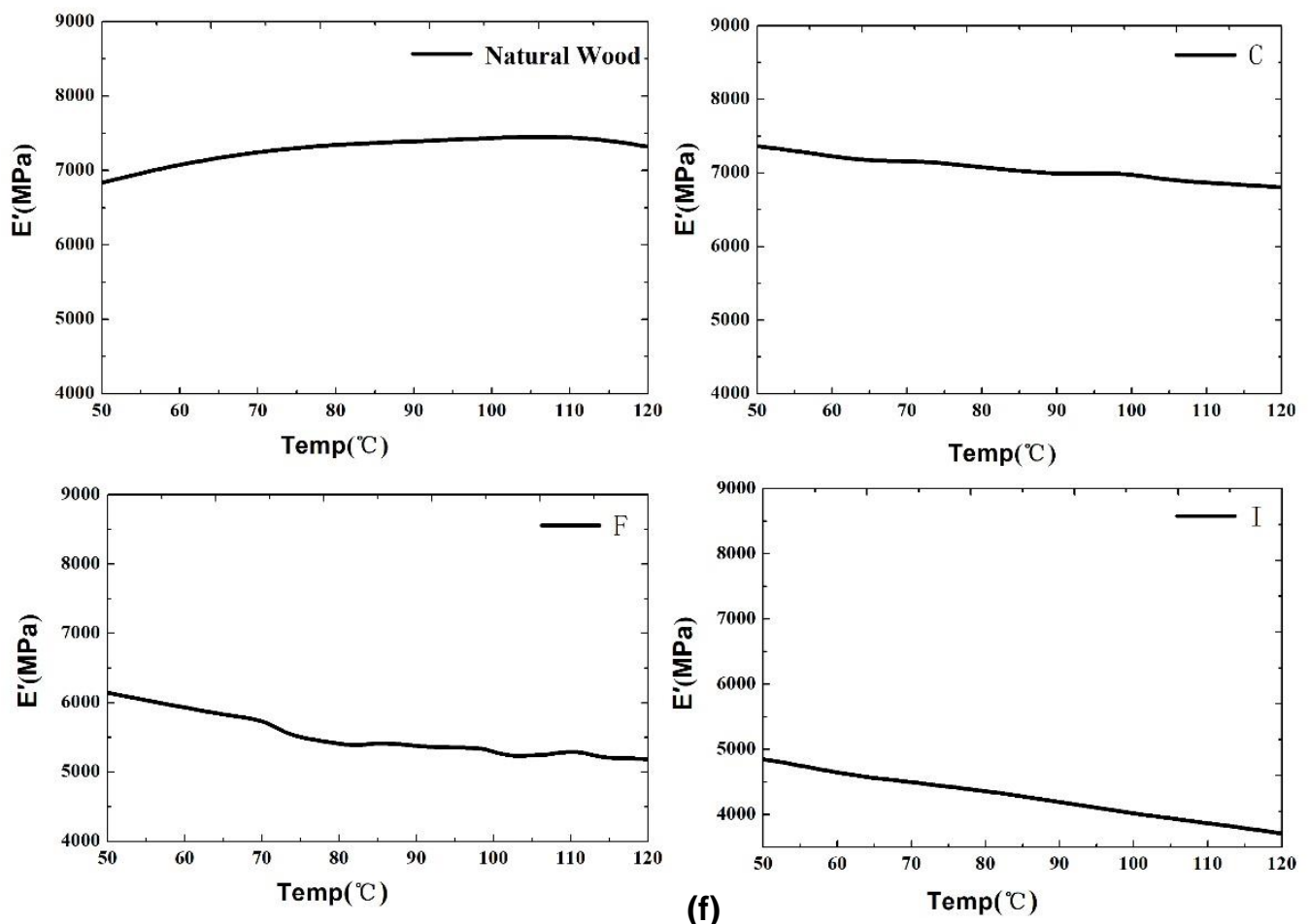

Fig. 2. Storage modulus curves of natural and modified wood: (a) 15\% urea; (b) 20\% urea; (c) $25 \%$ urea; (d) $15 \%$ MUF; (e) $20 \%$ MUF; and (f) $25 \%$ MUF contents

A superior interfacial adhesion between the wood fiber and the wood modifier occurred, which allowed a greater stress transfer at the inter-phase (Cai et al. 2008; Islam et al. 2012; Wang et al. 2017). The $E^{\prime}$ was associated with the elastic response of the 
composite, and it indicated the stiffness of the material. The plasticity of wood was enhanced with modification.

\section{Damping Parameter (tan $\delta)$ Analysis}

Tan $\delta$ was associated with the degree of molecular mobility in the polymeric material. A high $\tan \delta$ indicated a high molecular mobility, while a low $\tan \delta$ value indicated less molecular mobility in the material. The $\tan \delta$ curves of the modified wood specimens are presented in Fig. 3. The glass transition temperatures of the natural and modified wood samples were identified between 60 and $90{ }^{\circ} \mathrm{C}$. The transitions were caused by the microscopic Brownian movement in the main chain motion of the amorphous region.
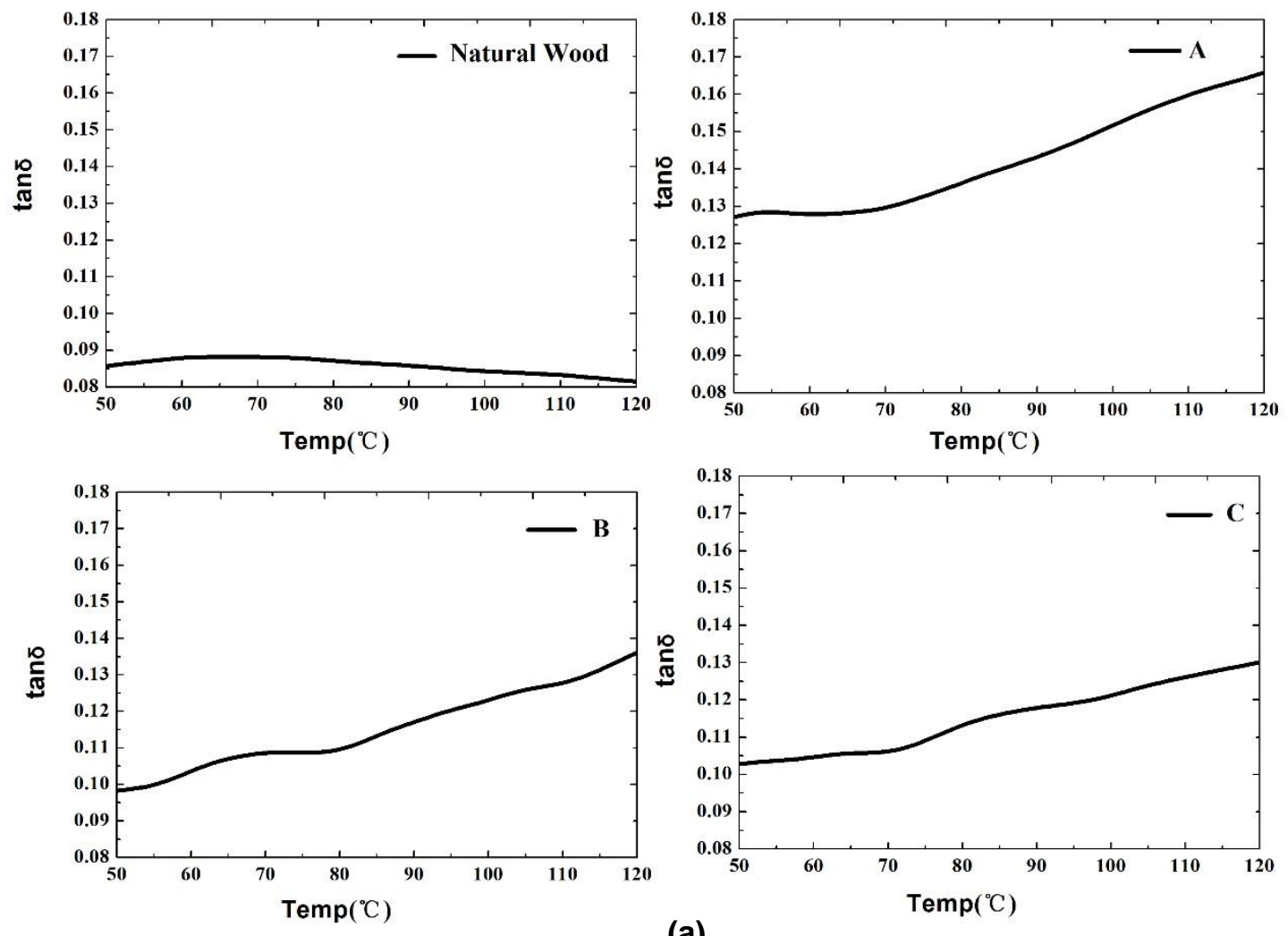

(a) 

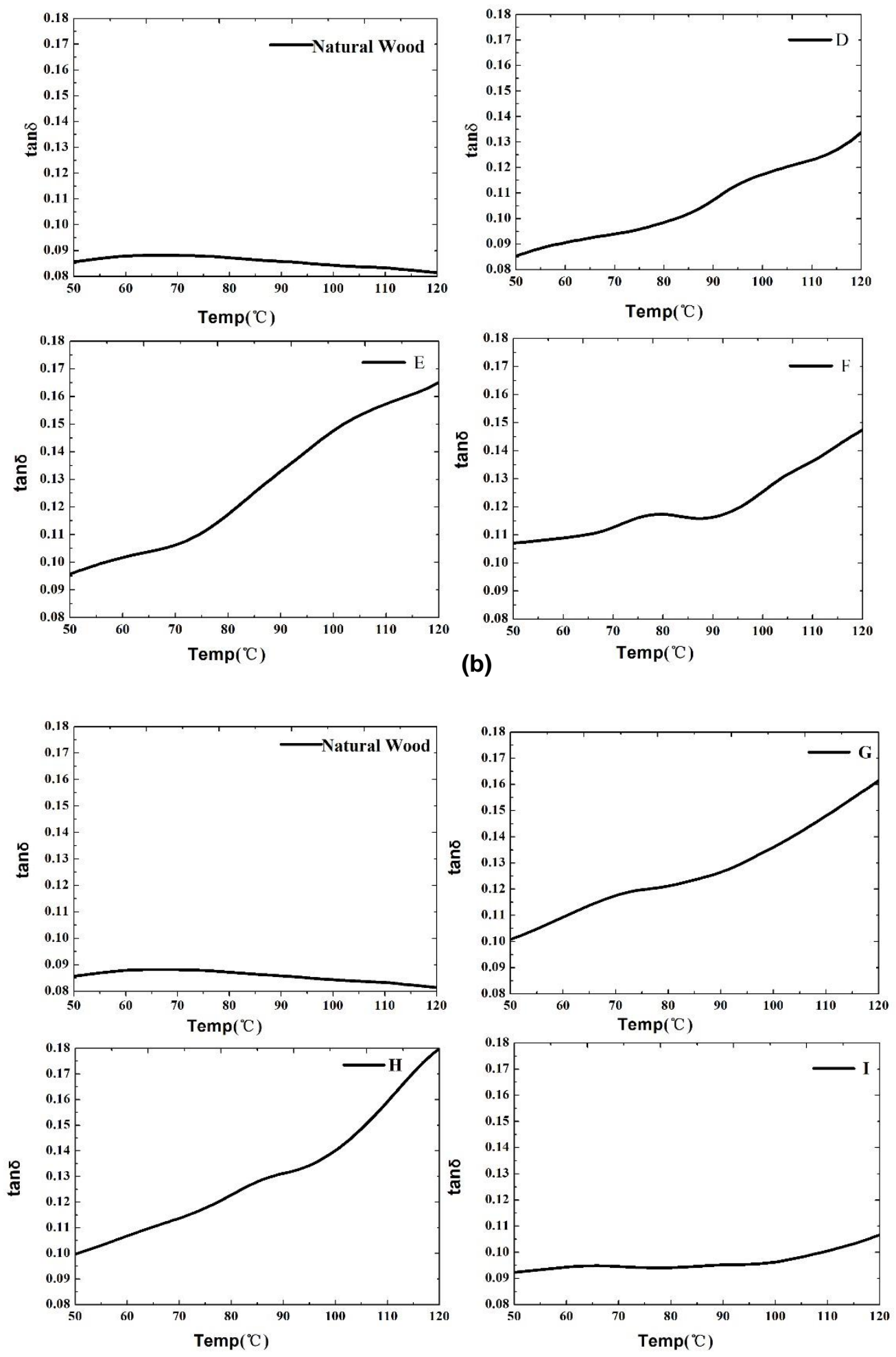

(c) 

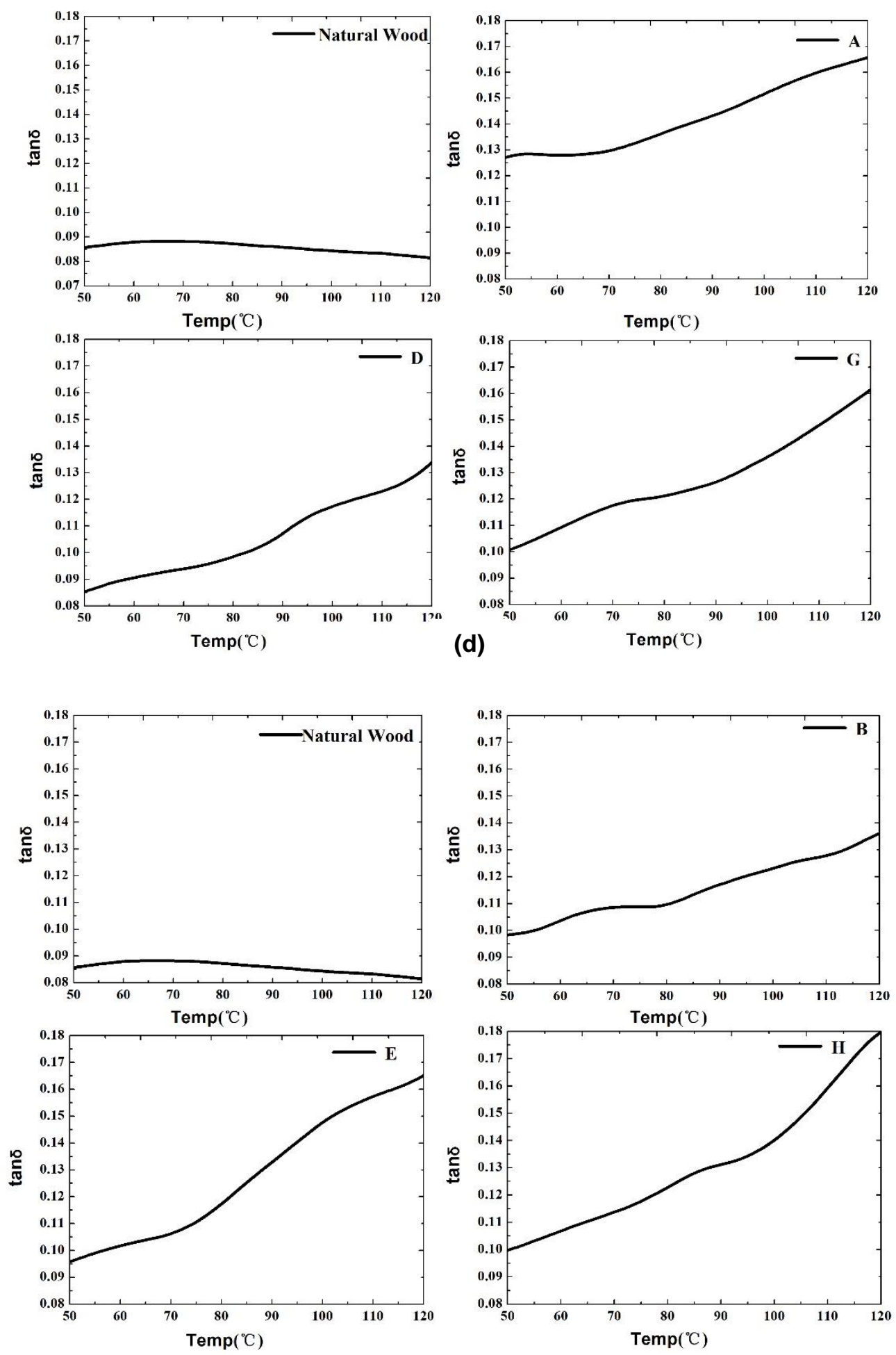

(e) 

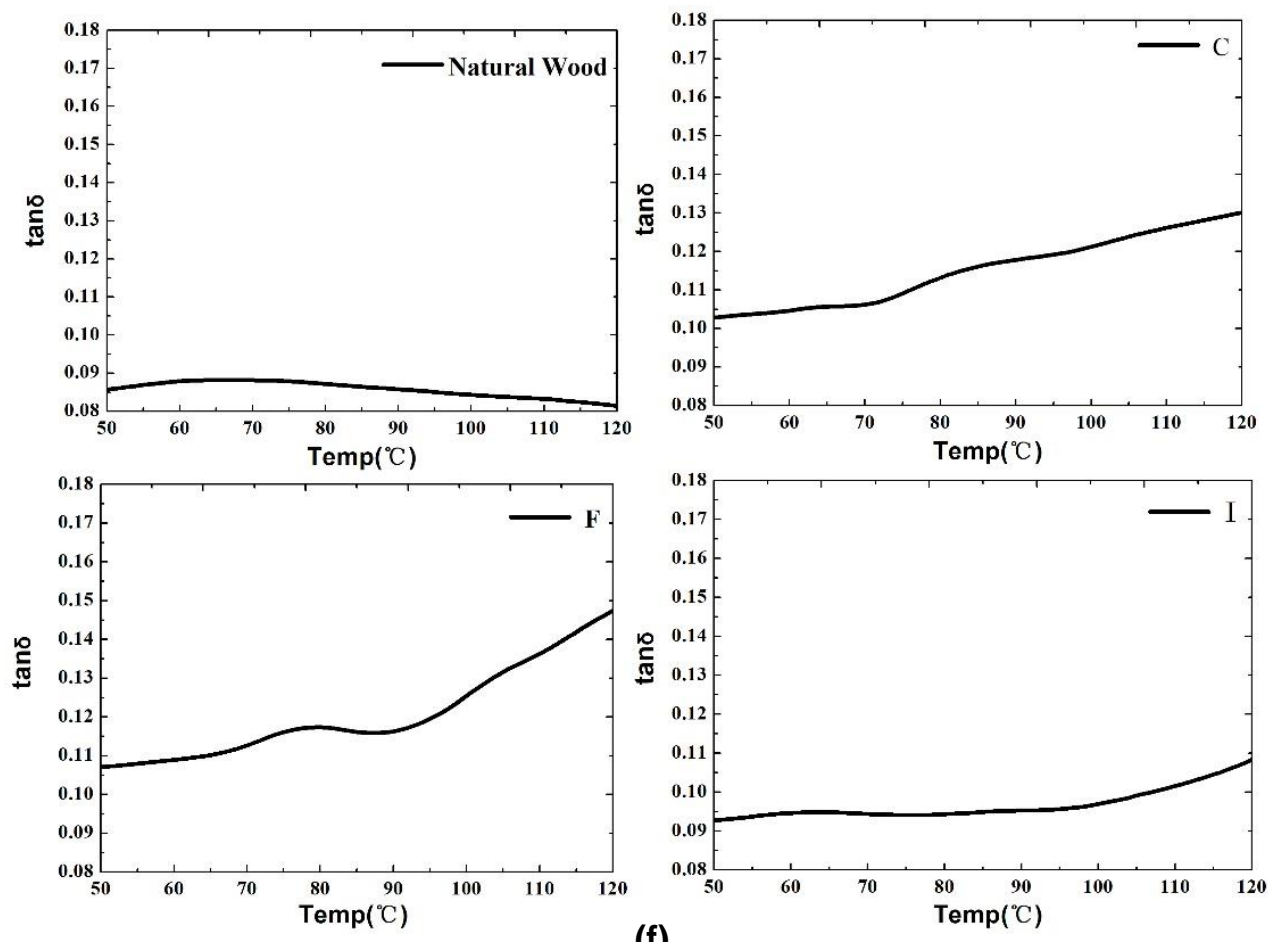

(f)

Fig. 3. Loss tangent curves of natural and modified wood: (a) $15 \%$ urea; (b) $20 \%$ urea; (c) $25 \%$ urea; (d) $15 \%$ MUF; (e) $20 \%$ MUF; and (f) $25 \%$ MUF contents

Altering the concentration of the MUF caused an apparent difference in $\tan \delta$. Figure 3 shows that the higher concentration of MUF yielded a higher $\tan \delta$ value, compared to the natural wood sample. The modified wood samples showed a higher $\tan \delta$ peak temperature for the temperature position of $\tan \delta$. The transition occurred around 65 ${ }^{\circ} \mathrm{C}$ for the natural wood sample, while the temperatures were $65{ }^{\circ} \mathrm{C}, 76{ }^{\circ} \mathrm{C}, 72{ }^{\circ} \mathrm{C}, 88^{\circ} \mathrm{C}$, $75{ }^{\circ} \mathrm{C}, 77{ }^{\circ} \mathrm{C}, 74{ }^{\circ} \mathrm{C}$, and $85^{\circ} \mathrm{C}$ for samples A, B, C, D, E, G, and $\mathrm{H}$, respectively. The change in $\tan \delta$ confirmed that the chemical reaction occurred in the region, where the interaction between the molecular chains was enhanced, which reduced the relaxation process of the molecules in wood. When the MUF was impregnated into the wood, a polymer composite was formed, and a well-defined platelet-MUF inter-phase was created. This inter-phase was sensitive to the surface modification of the modifier, the compatibility between the wood fiber, and the polymer matrix. The functional groups of the MUF were more compatible with the wood fiber, and stronger polymer-wood adhesion was formed, so a better performance was obtained for the modified wood samples (Mohanty et al. 2006). The more compatible the wood fiber and the modifier were, the better the mechanical properties of the wood, including surface hardness, modulus elasticity, abrasion resistance, water repellency, and dimensional stability. The bonding strength increased as the wood modifier content was increased, confirming that a chemical reaction in situ polymerization reaction occurred during the modification. The effect that the concentration of urea had on the $\tan \delta$ value was not obvious, demonstrating there was no strong chemical connection between the urea, the wood, and the newly formed hydrogen bond. 


\section{Mechanism of Wood Modifications by MUF}

Impregnation of solid wood with water-soluble MUF resin has led to a markable improvement of surface hardness and modulus of elasticity (MOE) (Cai et al. 2007). Melamine as a modifier has been used to form melamine-urea-formaldehyde (MUF) resin with higher mechanical properties and water resistance (Ding et al. 2020, 2021). The synthesis of MUF resins is a two-step process consisting of the methylolation stage of amino groups and condensation of methylols to form polymeric chains (Siimer et al. 2008). MUF resins have a complicated structure, which contains two monomers reactive with formaldehyde in the polymer. A large variety of structural moieties can provide reactive sites for the modification of wood. The preceding work confirmed that the MUF not only can fill the wood cell walls and the amorphous region of cellulose fibrils, but it can also form bonds with the groups of wood cell due to the abundant active groups in the MUF by the FTIR analysis (Cai et al. 2010; Lang et al. 2014). Based on the authors' previous report, the absorbances corresponding to major functional groups changes at 3590 to $3300 \mathrm{~cm}^{-1}$, 2950 to $2840 \mathrm{~cm}^{-1}, 2986 \mathrm{~cm}^{-1}, 1610 \mathrm{~cm}^{-1}$, and 1160 to $1052 \mathrm{~cm}^{-1}$, can be assigned as $\mathrm{NH}_{2}$ stretching vibration, aliphatic $\mathrm{CH}_{2}$ stretching vibration, $\mathrm{C}-\mathrm{NH}_{2}$ stretching vibration, $\mathrm{NH}$ bending vibration, and $\mathrm{NH}$ bending vibration, respectively. This is due to the stronger bonding between triazine carbons of MUF and wood cells (Lang et al. 2014). Meanwhile, the studies also showed the reaction mechanism of MUF and wood by 13C NMR quantitative analysis (Liang et al. 2020). After modification by MUF, the wood samples displayed higher storage modulus even at higher temperature (Nagamadhu et al. 2020). Therefore, the cross-linking reaction between the MUF pre-polymer and wood fiber improved the viscoelastic and dynamic properties of wood.

\section{CONCLUSIONS}

1. The stress relaxation (SR) and the dynamic mechanical properties were highly sensitive to the concentrations of the melamine urea formaldehyde (MUF) and the urea. The SR of the modified wood samples indicated a lower value than the natural wood samples.

2. The storage modulus $\left(E^{\prime}\right)$ value of the modified wood samples demonstrated a similar trend. The higher $\tan \delta$ value revealed a greater plasticity of the wood after the chemical modification.

3. The results confirmed that the wood modifier penetrated into the wood cell and a chemical reaction occurred between the functional groups of $-\mathrm{NHCH}_{2} \mathrm{OH}$ (methylolurea groups) and the carboxyl $-\mathrm{C}=\mathrm{O}$ group (wood). The hydroxyl and the amino groups from the MUF modifier was in situ polymerized with the hydroxyl groups (wood). The covalent in situ polymerization network improved the viscoelastic and dynamical mechanical properties.

\section{ACKNOWLEDGMENTS}

The research was supported by the China Postdoctoral Science Foundation (2017M621234), Heilongjiang Province Natural Science Foundation (LH2020C002), Heilongjiang Province Postdoctoral Science Foundation (LBH-Z17029), and the Youth Talent Foundation of Northeast Agricultural University (17QC31).

Lang et al. (2022). “Wood-MUF composite properties," BioResources 17(1), 1015-1030. 1027 


\section{REFERENCES CITED}

Cai, X., Riedl, B., Zhang, S. Y., and Wan, H. (2007). "Formation and properties of nanocomposites made up from solid aspen wood, melamine-urea-formaldehyde, and clay," Holzforschung 61(2), 148-154. DOI: 10.1515/HF.2007.027

Cai, X. L., Riedl, B., Zhang, S. Y., and Wan, H. (2008). "The impact of the nature of nanofillers on the performance of wood polymer nanocomposites," Composites Part A: Applied Science and Manufacturing 39(5), 727-737. DOI:

10.1016/j.compositesa.2008.02.004

Cai, X., Riedl, B., and Zhang, S., Y. (2010). "Montmorillonite nanoparticle distribution and morphology in melamine-urea-formaldehyde resin-impregnated wood nanocomposite," Wood and Fiber Science 42(3), 285-291.

Ding, Z. J., Ding, Z. Q., Ma, T. L., and Zhang, H. (2020). "Condensation reaction and crystallization of urea-formaldehyde resin during the curing process," BioResources 15(2), 2924-2936

Ding, Z. J., Ding, Z. Q., Ma, T. L., and Zhang, H. (2021). "Acidic buffering capacity and curing process of melamine-urea-formaldehyde resin," International Journal of Adhesion and Adhesives 104(140), article no. 102756. DOI: 10.1016/j.ijadhadh.2020.102756

Ding, Z., Ding, Z., Zhang, D., and Chao, C. (2021). "The hydrolytic stability and structure of the cured melamine-urea-formaldehyde resin," International Journal of Adhesion and Adhesives 104, article no. 102576, 1-21. DOI: 10.1080/00218464.2021.1930536

Düzkale Sözbir, G., Bektaş, İ., Kiliç Ak, A., and Erkan, S. (2021). "Pine wood modification via an antifungal oil - Heat treatment and its effect on annual wood rings," BioResources 16(3), 4731-4742. DOI: 10.15376/biores.16.3.4731-4742

Fabiyi, J. S., Fuwape, J. A., and Olufemi, B. (2011). "Surface chemistry and thermomechanical analysis of some Nigerian wood species," Thermochimica Acta 524(2), 80-87. DOI: 10.1016/j.tca.2011.06.018

George, J., Bhagawan, S. S., and Thomas, S. (1996). "Thermogravimetric and dynamic mechanical thermal analysis of pineapple fiber reinforced polyethylene composites," Journal of Thermal Analysis and Calorimetry 47(4), 1121-1140. DOI: 10.1007/bf01979452

Hon, D. N. S., and Qu, N. H. (1989). "Thermoplasticization of wood - I - Benzylation of wood," Journal of Polymer Science Part A: Polymer Chemistry 27(7), 2457-2482. DOI: 10.1002/pola.1989.080270725

Islam, M. S., Hamdan, S., Talib, Z. A., Ahmed, A. S., and Rahman, M. R. (2012). "Tropical wood polymer nanocomposite (WPNC): The impact of nanoclay on dynamic mechanical thermal properties," Composites Science and Technology 72(16), 1995-2001. DOI: 10.1016/j.compscitech.2012.09.003

Kaymakci, A., and Bayram, B. C. (2021). "Evaluation of heat treatment parameters' effect on some physical and mechanical properties of poplar wood with multi-criteria decision making techniques," BioResources 16(3), 4693-4703. DOI: 10.15376/biores.16.3.4693-4703

Kelley, S. S., Rials, T. G., and Glasser, W. (1987). "Relaxation behavior of the amorphous components of wood," Journal of Materials Science 22(6), 617-624. DOI: 10.1007/BF01160778

Lang et al. (2022). "Wood-MUF composite properties," BioResources 17(1), 1015-1030. 1028 
Kiziltas, A., Gardner, D. J., Han, Y., and Yang, H. S. (2011). "Dynamic mechanical behavior and thermal properties of microcrystalline cellulose (MCC)-filled nylon 6 composites," Thermochimica Acta 519(1-2), 38-43. DOI: 10.1016/j.tca.2011.02.026

Kumar, S. (1994). "Chemical modification of wood," Wood and Fiber Science 26(2), 270-280.

Kuo, P. Y., Wang, S. Y., Chen, J. H., Hsueh, H. C., and Tsai, M. J. (2009). "Effects of material compositions on the mechanical properties of wood-plastic composites manufactured by injection molding," Materials and Design 30(9), 3489-3496. DOI: 10.1016/j.matdes.2009.03.012

Lang, Q., Bi, Z., and Pu, J. W. (2014). "Characterization of chemical wood modification with MUF pre-polymer on fast-growing wood," Wood and Fiber Science 46(3), 311321.

Lang, Q., She, Y., Chen, H. Y., and Pu, J. W. (2013). "Poplar wood-methylolurea composites prepared by in situ polymerization," Journal of Applied Polymer Science 130(2), 933-938. DOI: 10.1002/app.39280

Liang, J. K., Li, Q., Wu, Z. G., Du, G. B., Li, T. H., Lei, H., and Li, Li. F. (2020). "Competitive polycondensation of model compound melamine-urea-formaldehyde (MUF) resin system by 13C NMR," Journal of Bioresources and Bioproducts 5(1), 60-66, DOI:10.1016/j.jobab.2020.03.007

Liu, H., Wu, Q., Han, G., Yao, F., Kojima, Y., and Suzuki, S. (2008). “Compatibilizing and toughening bamboo flour-filled HDPE composites: Mechanical properties and morphologies," Composites Part A: Applied Science and Manufacturing 39(12), 1891-1900. DOI: 10.1016/j.compositesa.2008.09.011

Liu, R., Peng, Y., and Cao, J. Z. (2014). "A comparison of various ionic surfactant modifiers used in in situ synthesis of organo-montmorillonite inside wood flour," Industrial Crops and Products 62, 387-394. DOI: 10.1016/j.indcrop.2014.09.014

Mohanty, S., Verma, S. K., and Nayak, S. K. (2006). "Dynamic mechanical and thermal properties of MAPE treated jute/HDPE composites," Composite Science and Technology 66(3-4), 538-547. DOI: 10.1016/j.compscitech.2005.06.014

Morlat, R., Godard, P., Bomal, Y., and Orange, G. (1999). "Dynamic mechanical thermoanalysis of latexes in cement paste," Cement and Concrete Research 29(6), 847-853. DOI: 10.1016/S0008-8846(99)00061-7

Nagamadhu, M., Ravi, K. S., Suraj, R., Manjunath, I. K. B., and Mohan, K. G. C. (2020). "Influence of extender on thermo-mechanical properties of melamine-ureaformaldehyde [MUF] for wood adhesive applications," Materials Today 24, 22742282. DOI:10.1016/j.matpr.2020.03.755

Obataya, E., Norimoto, M., and Gril, J. (1998). "The effects of absorbed water on dynamic mechanical properties of wood," Polymer 39(14), 3059-3064. DOI: 10.1016/S0032-3861(97)10040-4

Ou, R. X., Xie, Y. J., Wang, Q. W., Sui, S. J., and Wolcott, M. P. (2014). "Effects of ionic liquid on the rheological properties of wood flour/high density polyethylene composites," Composites Part A: Applied Science and Manufacturing 61, 134-140. DOI: 10.1016/j.compositesa.2014.02.017

Pothan, L. A., Oommen, Z., and Thomas, S. (2003). "Dynamic mechanical analysis of banana fiber reinforced polyester composites," Composites Science and Technology 63(2), 283-293. DOI: 10.1016/s0266-3538(02)00254-3

Shinoj, S., Visvanathan, R., Panigrahi, S., and Varadharaju, N. (2011). "Dynamic mechanical properties of oil palm fibre (OPF)-linear low density polyethylene

Lang et al. (2022). "Wood-MUF composite properties," BioResources 17(1), 1015-1030. 1029 
(LLDPE) biocomposites and study of fibre-matrix interactions," Biosystems Engineering 109, 99-107.

Siimer, K., Christjanson, P., Kaljuvee, T., Pehk, T., Lasn, I., and Saks, I. (2008). "TGDTA study of melamine-urea-formaldehyde resins," Journal of Thermal Analysis and Calorimetry 92(1), 19-27. DOI: 10.1007/s10973-007-8721-4

Sreekala, M. S., Kumaran, M. G., Joseph, R., and Thomas, S. (2001). "Stress-relaxation behaviour in composites based on short oil-palm fibers and phenol formaldehyde resin," Composites Science and Technology 61(9), 1175-1188. DOI: 10.1016/S02663538(00)00214-1

Tanimoto, T., and Nakano, T. (2012). "Stress relaxation of wood partially noncrystallized using aqueous $\mathrm{NaOH}$ solutions," Carbohydrate Polymer 87(3), 21452148. DOI: 10.1016/j.carbpol.2011.10.036

Wang, X. Q., Wang, F., Yu, Z. M., Zhang, Y., Qi, C. S., and Du, L. X. (2017). “Surface free energy and dynamic wettability of wood simultaneously treated with acidic dye and flame retardant," Journal of Wood Science 63(3), 271-280. DOI: 10.1007/s10086-017-1621-8

Zhu, X. D., Yi, S. L., Gao, Y., Zhao, Y. T., and Qiu, Y. Q. (2017). “Mechanical evaluation and XRD/TG investigation on the properties of wooden dowel welding," BioResources 12(2), 3396-3412. DOI: 10.15376/biores.12.2.3396-3412

Article submitted: August 16, 2021; Peer review completed: October 4, 2021; Revised version received: November 26, 2021; Accepted: November 28, 2021; Published: December 16, 2021.

DOI: $10.15376 /$ biores.17.1.1015-1030 